\title{
A Study Exploring the Collaborative Relationships Among Taiwanese Fishery Scientists
}

\author{
Chia-Hsiang Chen and Hao-Ren Ke \\ Graduate Institute of Library \& Information Studies, \\ National Taiwan Normal University, Taiwan \\ 80015003e@ntnu.edu.tw; clavenke@ntnu.edu.tw
}

\begin{abstract}
Background. Collaborative relationships support the progress of scientific research by providing a collaborator access to resources, skills, information, and technologies. Studies have highlighted the importance of collaborative relationships among scientists. However, less attention has been paid to the characteristics of the relationships.

Objectives. This study identified two key concepts, intellectual and social, as a theoretical approach to investigate collaborative relationships among scientists. Methods. Semi-structured interviews were conducted with 27 Taiwanese fishery scientists at the Taiwan Fisheries Research Institute, the Academia Sinica, the National Taiwan University, the National Taiwan Ocean University, and the National Museum of Marine Biology \& Aquarium.

Results. The results reveal that intellectual relationships among fishery scientists involve solving research puzzles collaboratively, giving informal comments on colleagues' work, and seeking professional recognition. Fishery scientists shape social relationships through academic activities such as collaborating with thesis supervisors as co-authors, selecting research partners according to their professional ability, and contributing to a local or global fish database for building individual professional identity. The fishery scientists considered coauthorship as a core requirement to maintain collaborative relationships. Support from thesis supervisors is important for facilitating collaborative relationships. This support affects the selection of known people as research partners, instead of selecting partners from different countries.
\end{abstract}

\section{INTRODUCTION}

Collaboration is an important factor in the progress of scientific research. Collaboration refers to "social processes whereby human beings pool their experience, knowledge and social skills with the objective of producing new knowledge, including knowledge as embedded in technology" (Bozeman \& Boardman, 2014, p. 2). Collaborative relationships have many benefits, and one of which is providing a mechanism for promoting intellectual fellowship and transfer knowledge and skills (Sprunger, 2017). Knowledge sharing plays a prominent role in collaboration relationships (Uzzi, 1997). Trust has been identified as a key factor influencing collaboration and knowledge sharing (Gulati, Lavie, \& Madhavan, 2011; Wulf \& Butel, 2017). Collaboration includes embedded social processes, and is strongly related to 
scientists' intellectual and social relationships (Katz \& Martin, 1997; Viale, 2010; Pallot, Martínez-Carreras, \& Prinz, 2010; Lee, 2015; Kucharska \& Kowalczyk, 2016).

Conference and journal publications are the primary scholarly communication channels and have enhanced information use, scientific knowledge, socioeconomic orientation, and information society development. A physics paper with 5,154 authors (published in Physical Review Letters) has broken all previous records for the largest number of contributors to a single research article (Aad, et al., 2015; Castelvecchi, 2015). Scientists' cooperation has become a high-profile scientific activity in the 21 st century and has gradually evolved into the most effective form of knowledge production (Claxton, 2005; Jucan \& Jucan, 2014; Groboljšek, Ferligoj, Mali, Kronegger, \& Iglič, 2014). In Science, Technology, Engineering and Mathematics (STEM) fields, more than $90 \%$ of the research studies and publications are collaborative (Bozeman \& Corley 2004; Bozeman \& Boardman, 2014). Collaboration among scientists is imperative (Bozeman \& Youtie, 2016, p. 1718). Fishery research is of keen interest to coastal countries around the world, which rely on collaboration of scientists to address fishery-related challenges (Carson, 1961; Hsu, Chen, Lin, Tseng, \& Chen, 2012). The world's fishery resources are suffering from heavy exploitation and environmental degradation. Fishery research is multi-disciplinary, and it needs collaboration in research to solve consistent and emerging fisheries problems. Fishery scientists depend seriously on an international exchange system to make accessible data and information from all available research sources (Cochrane, 2002). Research on fishery collaboration began in the 1990s. It involves shared responsibility, mutual trust, funding opportunity and shape a society's social interaction (Payne, Cotter, \& Potter, 2008). Resources and funding are required to encourage collaboration among scientists. Cooperative activities help to democratize science and maintain credibility among academic communities (Bozeman \& Boardman, 2014).

Taiwan is an island located in the subtropical Asia-Pacific region. According to the Food and Agriculture Organization (FAO, 2018) world fisheries production statistics for 2016, Taiwan was ranked 23rd among the world's top fisheries producers and was one of the most important high-seas fishing countries. A sustainable approach to fisheries will help to protect our natural resources and assure the availability of fishery resources to future generations. Fisheries are an important part of Taiwan's economy. Fisheries refer to organized human activities to catch fish and other aquatic species. The fisheries industry is engaged in fisheries production, and it may involve fishing and aquaculture. In the past five decades, Taiwanese fishery scientists have made substantial contributions to sustainable fisheries development (Chen, 1990; Taiwan Fisheries Agency, 2018). With its newly recognized role as a major supplier of progressive technology in fisheries, Taiwan aims to promote collaborative relationships and create scientific knowledge by conducting events such as conferences, symposia, and training programs for aiding countries with a developing fisheries industry so that they can learn from the experiences of Taiwan.

Girard and Du Payrat (2017) found that relational characteristics serve an important role in collaboration, and provide a collaborator access to new technologies in fisheries. For instance, in order to learn more about a species' habitat preferences and to prevent overfishing, the use of electronic recording devices, such as satellite archival tags technology, has made possible long term recording, and both Taiwan and Japan have collaborated to install the tags and analyze satellite data together (Lin, 2019, June 6). By using the advantages of information exchange and sharing, partners can work together toward an idea and publish their work. Studies have presented the importance of relationships for collaboration among scientists (Gulati, Nohria, \& Zaheer, 2000; Bikard, Murray, \& Gans, 2015). However, less attention has been paid to the characteristics of the relationships (Monge \& Contractor, 2001; 
Gulati, Dialdin, \& Wang, 2002; Borgatti \& Cross, 2003). This study identified two key concepts of collaborative relationships among scientists, namely, intellectual and social.

Past research has found a relation between collaboration and intellectual dependence, including formal co-authorship and informal commentary among scientists (de Solla Price, 1963; de Solla Price \& Beaver, 1966; Crane, 1972; Laband \& Tollison, 2000). Intellectual content refers to new ideas, learning techniques, careers, discovery processes, and reward systems (Merton, 1968; Chubin, 1976; Frickel \& Gross, 2005). The intellectual activities include formatting key ideas, solving problems, deciding which study to conduct, performing activities to enhance professional recognition (such as publishing articles and books), engaging in discussions and connecting with colleagues, attending conferences, providing informal comments on each other's work or experience, and developing a meaningful sense of intellectual activities. Scientists maintain intellectual traditions to obtain peer recognition and rewards (Mullins, 1972; Birnholtz, 2007; Iglič, Doreian, Kronegger, \& Ferligoj, 2017).

The second concept involved in collaboration relationships is social, which refers to both interpersonal relationship and the social capital embedded in them. Social relationships are reflected in: (1) communication (serious discussion about ongoing research), (2) coauthorship (a more intimate association with a topic), (3) a teacher apprenticing or mentoring a student, and (4) colleagueship (at the basic level, two scientists working in the same laboratory (Mullins \& Mullins, 1973, p.19). Social relationship, "the social interaction of shared activity" (Holt, 1993, p.542), is an important factor in successful collaborative relationships, because scientists can leverage this relationship to identify and connect with experts, realize a new idea, or even obtain career development opportunities (Mullins \& Mullins, 1973; Filho, Machado-da-Silva, \& Rossoni, 2010; Muriithi, Horner, Pemberton, \& Wao, 2018).

This study identified two key concepts, intellectual and social, and used them as a theoretical approach to investigate collaborative relationships among scientists. In particular, we analyzed how intellectual and social relationships shape the collaborative relationships among fishery scientists. The research questions are:

- What kinds of intellectual relationships shape collaborative behavior?

- What kinds of social relationships shape collaborative behavior?

\section{LITERATURE REVIEW}

In this section, the two concepts of intellectual and social relationships are introduced in the context of research collaboration.

\section{Intellectual Relationship}

Intellectual collaboration is defined as "more broadly to include collegial commentary, both individually and in workshops and seminars at professional meetings and other universities, and comments by journal editors and referees" (Laband \& Tollison, 2000, p.656).

Collaborative relationships are influenced by scientists' work styles. Scientists may collaborate for an intellectual activity and obtain results from others (Beaver, 2001; Hara, Solomon, Kim, \& Sonnenwald, 2003; Sonnenwald, 2007). This study categorized intellectual relationships into three types: solving research puzzles in related intellectual problems (Mullins, 1972), providing informal comments on each other's work or exchanging ideas (Lacy \& Busch, 1983; Poland, 1991, Laband \& Tollison, 2000), and seeking recognition and rewards (Kraut, Galegher, \& Egido ,1987; Zhang, Bu, Ding, \& Xu, 2018). 
The first component is solving research puzzles in related intellectual problems. Scientific knowledge has certain material and intellectual content (Polanyi, 1958). In the 1970s, a group of scholars of science and technology research studied scientists' practical scientific work in a laboratory to explain why experimental work is a key factor of intellectual activities. The laboratory is the setting where the biggest experimental contribution is made. The important intellectual components of laboratory research include learning to watch and explore, skills, and tacit knowledge. The laboratory opens up new horizons in terms of knowledge production and building social worlds in the sciences (Latour \& Woolgar, 1986; Sismondo, 2010).

Mullins (1972) analyzed the then new discipline of molecular biology, and found that scientists' intellectual activities included paradigm development, successful problem and puzzle solving. Paradigm development was observed among a group of experts and its impact was felt in their change in experience and specialty. Hence, paradigm development could influence researchers' subsequent research and publications, especially in solving problems and puzzles successfully.

The second component is informal comments on each other's work or exchanging ideas. According to a qualitative interview study, Lacy and Busch (1983) mentioned that some researchers were concerned about the lack of communication among agricultural scientists. Although scientists are involved in intellectual processes, they do not use new media communication tools on a regular basis in the field of science and technology. The nature of the intellectual leadership fosters increased interaction (Lacy \& Busch, 1983; Poland, 1991).

Hara, Solomon, Kim and Sonnenwald (2003) conducted a qualitative study, described the collaboration among a group of natural science scientists, and considered how their experiences were socially shaped. Organized collaboration factors were influenced by: (1) personal compatibility, including similar approaches to science, working styles writing styles, mutual respect, and trust; (2) work connections, referring to scientists connecting with others in different research groups; (3) existing incentives, both external (e.g., funding, publications, and prestige) and internal (e.g., such as solving interesting research problems and personal compatibility); and (4) socio-technical infrastructure, including awareness, access (to other collaborators), communication mechanism, and organizational culture and structure.

The third component is seeking recognition and rewards. Kraut, Galegher and Egido (1987) conducted semi-structured interviews with 50 scientists from the fields of psychology, management science, and computer science. Collaboration relationships provide intellectual and social benefits. Physical proximity is a key factor when conducting professional meetings with colleagues. The scientists had relative freedom to select their research partners and topics, had long and flexible deadlines for their research, and were rewarded through reputation and recognition.

Scientific collaboration is essential for solving problems and breeding innovation. Most scientists must make decisions on a daily basis about selecting potential collaborators or accepting collaboration invitations from others. The key motivations for a scientist to collaborate with a famous scientist are as follows: obtain highly productive equipment, increase the visibility of their work, and enhance their recognition (Zhang, Bu, Ding, \& Xu, 2018).

This study examined the three components of intellectual relationships to understand what kinds of intellectual relationships shaped fishery scientists' collaborative behavior. 


\section{Social Relationships}

Social relationships are related to interpersonal interactions, such as collaboration activities, among scientists in an organization or other social departments. Social relationships, such as acquaintances, mutual trust and study completion, are the key success factors in the resource acquisition process. Scientists first determine who the partner is and then decide what type of resource can be provided or exchanged in the social relationships, such as limited access data, culture details, collective decisions, and reputation (Jones, Hesterly, \& Borgatti, 1997; Bouty, 2000). According to a relational view, physical proximity mediates the relationships among knowing, valuing, access and cost. Social relationships are built on three characteristics: the extent to which a person knows and values the expertise of another, the accessibility of a resource and source, and the possibility of asking others for assistance. Thus, scientists perform better and contribute to interpersonal resources for increasing productivity and solving problems at work (Borgatti \& Cross, 2003).

This study categorized social relationships into three components, namely, co-authorship (Mullins \& Mullins, 1973; Filho, Machado-da-Silva, \& Rossoni, 2010), mentorship (Zuckerman, 1977; Leahey, 2016), and resource sharing (Jones, Hesterly, \& Borgatti, 1997; Leahey, 2016).

The first component is co-authorship. Co-authorship is a traditional and visible form of a social relationships among scientists (Mullins \& Mullins, 1973; Filho, Machado-da-Silva, \& Rossoni, 2010), research shows co-authorship receives more citations (Lee \& Bozeman, 2005; Gaughan \& Ponomariov, 2008). Co-authorship refers to multiple people authoring together, despite the fact that “... it is possible for individuals to be involved in research collaborations but not be named as authors. For example, some of those persons who pool their experience, knowledge and social skills, include research technicians, computer programmers, research managers and others who make a significant contribution but are not generally included as co-authors" (Bozeman \& Youtie, 2016, p.1719).

The second component is mentorship. Zuckerman (1977) studied various Nobel laureates and clarified the importance of mentor-apprentice pairings for a successful scientific career. He presented mentors' remarkable influence on the scientific productivity, quality, and excellence of later Nobel laureates. He found that the majority intentionally chose their academic mentors, and that many had worked under a Nobel laureate. This study revealed strong academic relationships among elite scientists. Kanigel (1993) supported Zuckerman's perspectives and mentioned that the training and mentoring relationships at the dissertation stage and in the postdoctoral phase is crucial in the career of a doctoral student.

There exists two styles of collaboration relationships: (1) engaging with professionals to access scientific expertise and to achieve a particular set of objectives and (2) mentoring, which has two subtypes - collaboration with students and collaboration through students (Hara, Solomon, Kim, \& Sonnenwald, 2003; Bozeman \& Corley, 2004; Leahey \& Reikowsky, 2008; Leahey, 2016). When scientists collaborate, they seek competitive advantage in work interests and skills, expertise, and perspectives. A mentorship style of collaboration is common among scholars who desire to help junior colleagues and graduate students to achieve research visibility (Bozeman \& Corley, 2004).

The third component is resource sharing. Bozeman and Corley (2004) examined data from 451 scientists and engineers at various academic research centers in the United States. Their results revealed that most scientists do not particularly include people from different countries in their selection of collaborators and they prefer to work with the people in their own work group. Most scientists select a collaborator who possesses the expertise that they 
lack, such as specialty areas and highly productive equipment (Wray, 2005; Boh, 2007; Leahey, 2016). Social media is becoming more important as geographic distance is becoming less important (Jones, Wuchty, \& Uzzi, 2008). Young scientists who collaborate more, rely on replacing retiring scientists (O’Brien, 2012).

Iglič, Doreian, Kronegger and Ferligoj (2017) analyzed Slovenian scientists in four scientific disciplines, namely mathematics, physics, biotechnology, and sociology. Their results showed that researchers spent about $40 \%$ of their research time working alone and $60 \%$ in collaboration. Collaboration helped scientists gain access to additional resources and to apply as a team for research funds. International collaboration is particularly important for researchers from a small country.

The current study analyzed the three components of social relationships to understand what kinds of social relationships shape fishery scientists' collaborative behavior.

\section{METHODS}

In the present study, a qualitative approach was adopted to examine intellectual and social relationships to explain how scientists select collaboration partners. Semi-structured interviews were conducted with 27 scientists at the Taiwan Fisheries Research Institute $(\mathrm{N}=14)$, the Academia Sinica $(\mathrm{N}=4)$, the National Taiwan University $(\mathrm{N}=2)$, the National Taiwan Ocean University ( $\mathrm{N}=3$ ), and the National Museum of Marine Biology \& Aquarium $(\mathrm{N}=4)$ from January 2016 to March 2017. These interviews lasted 45 to 90 minutes. Table 1 presents the demographics of the participants. The main questions used in the interviews were:

Q1. What research project are you currently working on?

Q2.Could you please describe your general research interests?

Q3. How do you solve research problems?

Q4. Are you currently a member of any professional society?

Q5.How do you establish connections with other scholars?

Q6. On what criteria do you base your identification and selection of collaboration partners?

Q7. What role does mentorship play in your academic career?

Q8. Do you have experience to do research on collaborative writing?

Q9. What kinds of social relationships shape your collaborative behavior?

The interviews were audio-recorded and later transcribed. The initial transcripts in the source language of Chinese were translated to English for conducting the analysis. The interviews were usually conducted at the respondents' offices, and the interview data were coded by two researchers, who annotated the dimensions occurring in the text of the transcripts (Hara, Solomon, Kim, \& Sonnenwald, 2003). Axial coding was applied to the interview data to identify categories in relationship to other categories and subcategories (Strauss, 1987; Walker \& Myrick, 2006), and to describe and extract interview data that fit into the analytical dimensions given in Table 2. 
Table 1. Demographics of the participants

\begin{tabular}{llc}
\hline Demographic & Profile category & $\begin{array}{c}\text { Number of } \\
\text { participants }\end{array}$ \\
\hline Affiliation (coding) & Taiwan Fisheries Research Institute & 14 \\
& Academia Sinica & 4 \\
& University & 5 \\
& National Museum & 4 \\
\hline Education & Doctoral Degree & 20 \\
& Master's Degree & 7 \\
\hline Position & Professor & 2 \\
& Assistant Professor & 3 \\
& Research Fellow & 7 \\
& Associate Research Fellow & 8 \\
& Assistant Researcher & 6 \\
& Assistant Research Specialist & 1 \\
\hline
\end{tabular}

Table 2. Examples of responses

\begin{tabular}{|c|c|c|}
\hline No. & Quotations & $\begin{array}{l}\text { Analytical } \\
\text { dimension }\end{array}$ \\
\hline 1. & $\begin{array}{l}\text { "My research is a state-of-the-art. It relies on reading journal articles } \\
\text { and experimenting to solve problems. It is also a responsibility of } \\
\text { scientists to sometimes discuss my work with senior researchers to } \\
\text { obtain more information or advice." (A1:24) }\end{array}$ & $\begin{array}{l}\text { Intellectual: } \\
\text { solving research } \\
\text { puzzles, and giving } \\
\text { informal comments } \\
\text { on colleagues' work }\end{array}$ \\
\hline 2. & $\begin{array}{l}\text { "My specialized research areas include fisheries, biostatistics, numerical } \\
\text { classification, ecology, and evolution. I have been investing in these } \\
\text { aspects for nearly } 30 \text { years. I have published about } 20 \text { fish illustrations. } \\
\text { Many people ask our lab to help identify fish" (B2: 90-91) }\end{array}$ & $\begin{array}{l}\text { Intellectual: } \\
\text { seeking recognition }\end{array}$ \\
\hline 3. & $\begin{array}{l}\text { "I am a member of the global stonefish research conservation } \\
\text { organization. I shared my data and research visibility." (D1:3-17) }\end{array}$ & $\begin{array}{l}\text { Intellectual: } \\
\text { seeking recognition }\end{array}$ \\
\hline 4. & $\begin{array}{l}\text { "The co-authorship began with a teacher-student relationship and a } \\
\text { professional orientation." (C1: 56-63) }\end{array}$ & $\begin{array}{l}\text { Social relationships: } \\
\text { co-authorship }\end{array}$ \\
\hline 5. & $\begin{array}{l}\text { "Although I graduated almost } 10 \text { years ago, I still rely on my } \mathrm{PhD} \\
\text { supervisor. If I encounter research difficulties, I always email or come } \\
\text { to school to ask his recommendation." (A10: 66-69) }\end{array}$ & $\begin{array}{l}\text { Social relationships: } \\
\text { mentorship }\end{array}$ \\
\hline 6. & $\begin{array}{l}\text { "I secured my PhD from Department of Zoology, Faculty of Science, } \\
\text { Stockholm University, in } 2012 \text {. My PhD supervisor is my most } \\
\text { frequently contacted scholar. I meet him once a year in Sweden and stay } \\
\text { in his laboratory to conduct research together. It is a mentoring } \\
\text { relationship." (C2: 52-53) }\end{array}$ & $\begin{array}{l}\text { Social relationships: } \\
\text { mentorship }\end{array}$ \\
\hline 7. & $\begin{array}{l}\text { "I contributed to the Fishbase database as an expert. More than } 30 \\
\text { foreign scholars visit my lab each year. More than } 1,000 \text { specimens } \\
\text { were collected together to increase the visibility of Taiwanese fish. This } \\
\text { effort was conducted to enable the establishment of academic contacts." } \\
\text { (D4: 21-24) }\end{array}$ & $\begin{array}{l}\text { Social relationships: } \\
\text { resource sharing }\end{array}$ \\
\hline
\end{tabular}




\section{RESULTS}

Scientific knowledge is intellectually bound by shared expertise, and scientists are connected through social relationships. We first characterize the intellectual relationships among fishery scientists, and then the social relationships.

Regarding the intellectual relationships among fishery scientists, all the interviewed participants preferred to read papers individually but preferred to conduct laboratory experiments together, which can be characterized as building intellectual relationships through solving a research puzzle. Another kind of activity that builds intellectual relationships is going to a physical library to read fish illustrations and discussing ideas with the thesis supervisor, senior colleagues, ship captains, aquaculture farmers, students, and team members. The methods of seeking recognition include identifying new fish specimens and attending associations' events, public seminars and public speeches. All the respondents mentioned that the experimental records were open to everyone in the laboratory, but not to the public outside the laboratory. Nine participants relied on electronic library resources instead of physical library materials. Moreover, the thesis supervisor is the core academic cycle member who is highly respected. Out of the 27 participants, only three did not keep in touch with their former thesis supervisor.

Considering the first research question of the present study, the results suggest that organizations should create an environment for sharing knowledge, such as a space (e.g., a breakroom) serving as a platform for communicating ideas; enhance physical and electronic library materials to meet the information needs of scientists; and encourage senior scientists to train juniors and afford them experiences to maintain their intellectual curiosity trajectory.

Regarding social relationships, the interviewees agreed that publishing a paper is the major goal of building and maintaining social relationships. On the issue of co-authorship, the following criteria were used for selecting research partners: professional ability (especially publishing and analytical ability), trust based on the recommendation of a supervisor or scholar that one knows, personality, proximity (to enable easy face-to-face discussions), and sense of responsibility. All the interviewed participants mentioned that the selection of collaboration partners is based on knowing the person. Moreover, they would not collaborate with a scholar from another country because of budget limitations and time constraints. All the participants mentioned that before submitting an English paper, they have to find a foreign scholar or pay money to proofread or edit their paper. Three participants mentioned that they had experience of bad collaboration that wasted time and resources, and produced no results.

Regarding the present study's second research question, fishery scientists shape social relationships by co-authoring with the thesis supervisor, selecting research partners according to professional ability, and contributing to a local or global fish database to increase research visibility. The criteria scientists use to select collaboration partners include professional ability, trust, personality, proximity, and sense of responsibility. These activities are associated with intellectual and social relationships of Taiwanese fishery scientists.

\section{DISCUSSION}

Some fisheries management scholars emphasize practical experience (learning by doing) and tacit knowledge as an important intellectual and social asset (Pálsson, 1995 \& 2000; Hoefnagel, Burnett, \& Wilson, 2006). This highlights the significance of expert network relationships in transferring tacit, complex knowledge and solving related intellectual problems between scientists. 
Scientists rely on collaborative relationships to access, examine and exploit knowledge resources. These scientists gradually nurture a spirit of mutual trust (Powell, 1998; Augier \& Vendelo, 1999; Puusa \& Eerikäinen, 2010). Mutual trust may explain why twenty-four respondents mentioned a mentoring style of collaboration as the main way to establish and facilitate intellectual relationships. Because of competition and limitation of research funding, all the respondents mentioned that the experiment records were for internal use only.

This research has shown that Taiwanese fishery scientists are not particularly cosmopolitan in their selection of collaborators. They tend to work with the people in their own work group. This aligns with the findings of previous studies that scientists followed mentor relationships (Bozeman \& Corley, 2004; Leahey, 2016) and less cosmopolitan collaboration (Bozeman \& Corley, 2004).

Co-authorship is considered a traditional and visible form of a social relationship among scientists (Mullins \& Mullins, 1973; Filho, Machado-da-Silva, \& Rossoni, 2010). Bozeman and Youtie (2016, p.1718) found co-authorship crediting problems fall into two categoriesexcluding deserving contributors or including undeserving ones. One respondent in this study mentioned that his team had this phenomenon. This study found that the selection criteria for research partners include professional ability, trust, personality, proximity, and responsibility. Personal acquaintance is an important factor in selecting collaboration partners, and the collaborators were chosen from the expert network members (Borgatti \& Cross, 2003).

The dominant communication media include meeting in person, telephoning, and emailing. Scientists prefer those traditional communication channels (Chung, Kwon, \& Lee, 2016). This study found that intellectual and social relationships are intertwined in Taiwanese fishery scientists' academic activities. Before Taiwanese fishery scientists submit an English research paper, they have to find a foreign scholar or pay for proofreading and editing service. Most of the respondents admit that collaborative work with native English speakers have many benefits. The language barrier is a common challenge for Taiwanese fishery scientists, which explains why the respondents preferred attending conferences in Taiwan.

The results indicate that proximity plays an important role in social relationships. This suggests that research institutions should increase the incentives for scientists to attend international conferences. Institutions should also host a high number of international conferences, or invite a high number of visiting scholars to create research visibility.

\section{CONCLUSION}

The present study examined the roles of the two important components of collaborative relationships among fishery scientists, namely, intellectual and social relationships. The study found that the intellectual relationships of fishery scientists include reading journal articles individually but experimenting collaboratively to solve research puzzles, conducting informal discussions with colleagues, and seeking international recognition.

Social relationships connect fishery scientists' collaborative behavior. As the primary goal of fishery scientists is to publish their research, they considered co-authorship as the core requirement to maintain social collaborative relationships. Obtaining support from a thesis supervisor is important for facilitating social relationships. This support helps in identifying known people as research partners, instead of selecting partners from other countries.

This study had a small sample size. Nevertheless, we have uncovered some insights on the factors for collaborative relationships among fishery scientists. Future studies and analyses should use these results to explore the related factors and implement appropriate solutions for developing scientific relationships among scientists. 


\section{REFERENCES}

Aad, G., Abbott, B., Abdallah, J., Abdinov, O., Aben, R., Abolins, M., ... Woods, N. (2015). Combined measurement of the Higgs boson mass in pp collisions at sqrt(s) $=7$ and 8 TeV with the ATLAS and CMS experiments. Physical Review Letters, 114, Article 191803(33). https://doi.org/10.1103/PhysRevLett.114.191803

Augier, M., \& Vendelo, M.T. (1999). Networks, cognition and management of tacit knowledge. Journal of Knowledge Management 3(4), 252-261. https://doi.org/10.1108/13673279910304005

Beaver, D.D. (2001). Reflections on scientific collaboration (and its study): Past, present, and future. Scientometrics, 52(3), 365-377.

Bikard, M., Murray, F., \& Gans, J.S. (2015). Exploring trade-offs in the organization of scientific work: Collaboration and scientific reward. Management Science, 61(7), 1473-1495.

Birnholtz, J.P. (2007). When do researchers collaborate? Toward a model of collaboration propensity. Journal of the American Society for Information Science and Technology, $58,2226-2239$.

Boh, W.F. (2007). Mechanisms for sharing knowledge in project-based organizations. Information and Organization, 17(1), 27-58.

Borgatti, S.P., \& Cross, R. (2003). A relational view of information seeking and learning in social networks. Management Science, 49, 432-445.

Bouty, I. (2000). Interpersonal and interaction influences on informal resources exchanges between R\&D researchers across organizational boundaries. Academy of Management Journal, 43(1), 50-65.

Bozeman, B., \& Boardman, C. (2014). Research collaboration and team science: A state-ofthe-art review and agenda. London: Springer.

Bozeman, B., \& Youtie, J. (2016). Trouble in paradise: Problems in academic research coauthoring. Science and Engineering Ethics, 22, 1717-1743.

Bozeman, B., \& Corley, E. (2004). Scientists' collaboration strategies: Implications for scientific and technical human capital. Research Policy, 33, 599-616.

Carson, R. (1961). The sea around us. New York: Oxford University Press.

Castelvecchi, D. (2015). Physics paper sets record with more than 5,000 authors. Nature, 15 May 2015. doi:10.1038/nature.2015.17567

Chen, L.C. (1990). Aquaculture in Taiwan. Oxford: Fishing News Books.

Chubin, D.E. (1976). State of the field: The conceptualization of scientific specialties. The Sociological Quarterly, 17(4), 448-476.

Chung, E., Kwon, N., \& Lee, J. (2016). Understanding scientific collaboration in the research life cycle: Bio- and nanoscientists' motivations, information-sharing and communication practices, and barriers to collaboration. Journal of the Association for Information Science \& Technology, 67(8), 1836-1848.

Claxton, L.D. (2005). Scientific authorship: Part 2. History, recurring issues, practices, and guidelines. Mutation Research/Reviews in Mutation Research, 589, 31-45.

Cochrane, K.L. (Ed.) (2002). A fishery manager's guidebook: Management measures and their application (FAO Fisheries Technical Paper, no. 424). Rome: FAO.

Crane, D. (1972). Invisible colleges: Diffusion of knowledge in scientific communication. Chicago: University of Chicago Press.

de Solla Price, D. (1963). Little science, big science. New York: Columbia University Press. 
de Solla Price, D., \& Beaver, D. (1966). Collaboration in an invisible college. American Psychologist, 21, 1011-1058.

FAO (2018). FAO yearbook. 2016 fishery and aquaculture statistics. Rome: FAO. Retrieved from www.fao.org/fishery/static/Yearbook/YB2016_USBcard/index.htm

Filho, E.R.G., Machado-da-Silva, C.L., \& Rossoni, L. (2010). The social and intellectual dimensions in the construction of scientific knowledge: The institutional theory in organization studies in Brazil. Brazilian Administration Review, 7(2), 136-154.

Frickel, S., \& Gross, N. (2005). A general theory of scientific/intellectual movements. American Sociological Review, 70(2), 204-232.

Gaughan, M., \& Ponomariov, B. (2008). Faculty publication productivity, collaboration, and grants velocity: Using curricula vitae to compare center-affiliated and unaffiliated scientists. Research Evaluation, 17(2), 103-110.

Girard, P. \& Du Payrat, T. (2017). An inventory of new technologies in fisheries. Issue paper for the OECD Green Growth and Sustainable Development (GGSD) Forum, 21 \& 22 November, 2017. Paris: OECD. Retrieved from www.oecd.org/greengrowth/GGSD_2017_Issue Paper_New technologies in Fisheries_WEB.pdf

Groboljšek, B., Ferligoj, A., Mali, F., Kronegger, I., \& Iglič, H. (2014). The role and significance of scientific collaboration for the new emerging sciences: The case of Slovenia. Teorija in praksa let., 51(5), 864-883.

Gulati, R., Dialdin, D.A., \& Wang, L. (2002). Organizational networks. In J.A.C. Baum (Ed.), The Blackwell companion to organizations (Chap.12, pp. 281-303). Malden, MA: Blackwell.

Gulati, R., Lavie, D., \& Madhavan, R. (2011). How do networks matter? The performance effects of interorganizational networks. Research in Organizational Behavior, 31, 207224.

Gulati, R., Nohria, N., \& Zaheer, A. (2000). Strategic networks. Strategic Management Journal, 21 (Special Issue), 203-215.

Hara, N., Solomon, P., Kim, S.-L., \& Sonnenwald, D.H. (2003). An emerging view of scientific collaboration: Scientists' perspectives on collaboration and factors that impact collaboration. Journal of the American Society for Information Science and Technology, 54, 952-965.

Hoefnagel, E., Burnett, A., \& Wilson, D.C. (2006). The knowledge base of co-management. In L. Motos, \& D. Wilson (Eds.), The knowledge base for fisheries management (Chap.4, pp. 85-108). Amsterdam: Elsevier

Holt, M. (1993). Knowledge, social relations, and authority in collaborative practices of the 1930s and the 1950s. College Composition and Communication, 44(4), 538-555.

Hsu, Y.K., Chen, S.C., Lin, C.Y., Tseng, C.T., \& Chen, K.C. (2012). Development of fisheries information systems for the Fisheries Research Institute of Taiwan. In The 8th Asian Conference for Information Technology in Agriculture, September 3-6 2012, Taipei, Taiwan.

Iglič, H., Doreian, P., Kronegger, L., \& Ferligoj, A. (2017). With whom do researchers collaborate and why? Scientometrics, 112(1), 153-174.

Jones, B.F., Wuchty S., \& Uzzi B. (2008). Multi-university research teams: Shifting impact, geography, and stratification in science. Science, 322, 1259-1262.

Jones, C., Hesterly, W., \& Borgatti, S. (1997). A general theory of network governance: Exchange conditions and social mechanisms. Academy of Management Review, 22(4), 911-945. 
Jucan, M.S., \& Jucan, C.N. (2014). The power of science communication. Procedia, 149, 461-466.

Kanigel, R. (1993). Apprentice to genius: The making of a scientific dynasty. Baltimore: Johns Hopkins University Press.

Katz, J.S., \& Martin, B.R. (1997). What is research collaboration? Research Policy, 26(1), 118.

Kraut, R.R., Galegher, J., \& Egido, C. (1987). Relationships and tasks in scientific research collaboration. Human-Computer Interaction, 3(1), 31-58.

Kucharska, W., \& Kowalczyk, R. (2016). Trust, collaborative culture and tacit knowledge sharing in project management: A relationship model. In Proceedings of the 13th International Conference on Intellectual Capital, Knowledge Management \& Organisational Learning, 14-15 October 2016, Ithaca College. Ithaca, New York, USA. doi:10.13140/RG.2.2.25908.04486

Laband, D., \& Tollison, R. (2000). Intellectual collaboration. Journal of Political Economy, 108(3), 632-662. doi:10.1086/262132

Lacy, W.B., \& Busch, L. (1983). Informal scientific communication in the agricultural science. Information Processing \& Management, 19(4), 193-202.

Latour, B., \& Woolgar, S. (1986). Laboratory life: The construction of scientific facts. New Jersey: Princeton University Press.

Leahey E., \& Reikowsky, R.C. (2008). Research specialization and collaboration patterns in sociology. Social Studies of Science, 38(3), 425-440.

Leahey, E. (2016). From solo investigator to team scientist: Trends in the practice and study of research collaboration. Annual Review of Sociology, 42, 81-100.

Lee, S.J. (2015). Growth behavior of research collaboration with heterogeneous colleagues and research commercial activities in Korean academics. In W. Cummings \& U. William (Eds.), The relevance of academic work in comparative perspective (Chap. 8, pp.121-138). Cham: Springer International Publishing.

Lee, S., \& Bozeman, B. (2005). The impact of research collaboration on scientific productivity. Social Studies of Science, 35(5), 673-702.

Lin, C.N. (2019, June 6). Team makes mahi-mahi discovery. Taipei Times, Thursday, June 6 2019, pp. 4. Retrieval from http://www.taipeitimes.com/News/taiwan/archives/2019/06/06/2003716445

Merton, R.K. (1968). The Matthew Effect in science. Science, 159 (3810), 56-63.

Monge, P., \& Contractor. N. (2001). Emergence of communication networks. In F.M., Jablin, \& L.L. Putnam (Eds.), The new handbook of organizational communication (Chap.12, pp. 440-502). Thousand Oaks, CA: SAGE Publications, Inc. doi: $10.4135 / 9781412986243$

Mullins, N.C. (1972). The development of a scientific specialty: The phage group and the origins of molecular biology. Minerva. 10 (1), 51-82.

Mullins, N.C., \& Mullins, C.J. (1973). Model for the development of sociological theories. In Theories and theory groups in contemporary American sociology, (chap. 2, pp.17-38). New York: Harper \& Row.

Muriithi, P., Horner, D., Pemberton, L., \& Wao, H. (2018). Factors influencing research collaboration in Kenyan universities. Research Policy, 47(1), 88-97.

O'Brien, T.L. (2012). Change in academic authorship, 1953-2003. Science Technology \& Human Values, 37(3), 210-234.

Pallot, M., Martinez-Carreras, M.A., \& Prinz, W. (2010). Collaborative distance. International Journal of e-Collaboration, 6(2), 1-32. doi:10.4018/jec.2010040101. 
Pálsson, G. (1995). Learning by fishing: Practical science and scientific practice. In Hanna, S., \& Munasinghe, M. (Eds.), Property rights in a social and ecological context: Case studies and design applications (chap. 8, pp.85-97) Washington, D.C.: Beijer International Institute of Ecological Economics and The World Bank.

Pálsson, G. (2000). Finding one's sea legs: Learning, the process of enskilment, and integrating fishers and their knowledge into fisheries science and management. In B. Neis, \& L. Felt (Eds.), Finding our sea legs: Linking fishery people and their knowledge with science and management (pp.26-40). St. John's, NL, Canada: ISER Books.

Payne, A., Cotter J., \& Potter., T. (2008). Advances in fisheries science: 50 years on from Beverton and Holt. Oxford: Blackwell.

Poland, J. (1991). Informal communication among scientists and engineers: A review of the literature. Science \& Technology Libraries, 11(3), 61-73.

Polanyi, M. (1958). Personal Knowledge: Towards a post-critical philosophy. Chicago: University of Chicago Press.

Powell, W. (1998). Learning from collaboration: Knowledge and networks in the biotechnology and pharmaceutical industries. California Management Review, 40(3), 228-240.

Puusa, A. \& Eerikäinen, M. (2010). Is tacit knowledge really tacit? Electronic Journal of Knowledge Management, 8(3), 307-318.

Sismondo, S. (2010). Studying laboratories: An introduction to science and technology studies (2nd ed.). Chichester: Wiley-Blackwell.

Sonnenwald, D.H. (2007). Scientific collaboration. Annual Review of Information Science and Technology, 41, 643-681.

Sprunger, J.G. (2017). The benefits of engaging in collaborative research relationships. Observer, 30, 42-43.

Strauss, A. (1987). Qualitative analysis for social scientists. Cambridge, UK: Cambridge University Press.

Taiwan Fisheries Agency. (2018). Fisheries of the Republic of China. Taipei: Taiwan Fisheries Agency.

Uzzi, B. (1997). Social structure and competition in interfirm networks: The paradox of embeddedness. Administrative Science Quarterly, 35(42), 35-67.

Viale, R. (2010). Knowledge-driven capitalization of knowledge. In R.Viale (Ed.), Methodology cognitivism. Vol.2, Cognition, science, and innovation (chap.14, pp.345336). Berlin: Springer-Verlag.

Walker, D., \& Myrick, F. (2006). Grounded theory: An exploration of process and procedure. Qualitative Health Research, 16, 547-559.

Wray, W.B. (2005). Rethinking scientific specialization. Social Studies of Science, 35(1), 151-164.

Wulf, A., \& Butel, L. (2017). Knowledge sharing and collaborative relationships in business ecosystems and networks: A definition and a demarcation. Industrial Management \& Data Systems, 117(7), 1407-1425.

Zhang, C., Bu, Y., Ding, Y., \& Xu, J. (2018). Understanding scientific collaboration: Homophily, transitivity, and preferential attachment. Journal of the Association for Information Science and Technology, 69(1), 72-86.

Zuckerman, H. (1977). Scientific elite: Nobel laureates in the United States. New York: Free Press. 